\title{
Challenges for Public Health Nutrition are immense - to be a good public health nutrition leader requires networking and collaboration
}

What do I see as the future challenges for Public Health Nutrition? A wealth of data will be coming out from large epidemiological studies, questioning some old truths and confirming others. Public health nutritionists will need to have an increasingly broad base of knowledge in order to master the field, and it seems very timely to initiate more active networking in order to foster collaboration and lobbying.

In a more philosophical exploration of leadership, what characteristics do we optimally want to see in a good, leading public health nutritionist? Probably the same profile as is needed for any leading scientist/practitioner, as outlined by Aristotle in the Nicomachean Ethics ${ }^{1}$. Leader virtues are not a set of principles but rather a state of mind or disposition, induced by personal and professional experiences in the field leading to a set of appropriate attitudes. Inspired by Aristotle, I argue that wisdom, curiosity, generous leadership and good communication skills are some of the most important traits that form a good public health nutrition leader.

The Giessen Declaration ${ }^{2}$ describes the New nutrition science as multidimensional and containing three dimensions: biological, social and environmental. The principles guiding nutritional science are described as ethics, coresponsibility and sustainability, governed by human rights and an understanding of evolution, history and ecology. Thus it has strong links to the production of foods, ecology and the environment, as well as a clear political edge.

Going back a bit in time, the legendary cardiologist Henry Blackburn many decades ago described how disagreements in the area of health and nutrition can easily appear due to differences in ways of looking at the problem $^{3,4}$. The clinical view looks at individual patients' risk of disease, concentrating on screening risk factors or looking for hereditary patterns of disease, dealing with cure or prevention of disease rather than general health promotion. The academic view is preoccupied with investigating the basic mechanisms at molecular or cellular level, trying to understand how nutrients interact with other compounds. The complexity of the human cell has already been revealed to a great extent through the human genome - but massive amounts of nutrigenetics and molecular nutrition need to be investigated further. This area is in constant flux because the final evidence will probably never be revealed or at least not in our lifetime. The public health view is concerned with the health of populations. Public health science and health promotion especially are concerned with social and political as well as environmental issues for optimal health. In public health science, several theories and frameworks guide the work; for health promotion especially the Ottawa Charter of Health Promotion ${ }^{5}$ is still going strong. A good public health nutritionist needs to take account of all three perspectives in day-to-day practice as well as in planning ahead.

So, what do we look for in a senior public health nutrition scientist, in the context of the New nutrition science, taking Henry Blackburn's description of how disagreements arise into account as well as the demands of any good scientific leader according to Aristotle?

Certainly, from the wisdom point of view, an ability to adapt to the new messages developed within molecular nutrition and nutrigenetics and to understand scientific findings in a vast number of areas. A possibility to understand evolving issues in depth as well as across disciplines. Included in the wisdom perspective is of course to know that nutritional science did not start to report its findings 10 years ago - with the introduction of electronically available publications. Thus the new nutrition scientist needs to be on the cutting edge of new science at the same time as having a depth of knowledge of historical findings. Due to the constantly developing field of knowledge, one of the important manners of wisdom is to be able also to say: 'I cannot answer that question, but I think I know somebody who can'.

Curiosity means that we never cease to look for or adopt new findings and never cease to question our old 'gold standards' and 'holy cows'. To be curious also includes an ability to collaborate over the borders, with scientists in adjacent areas, and to acquire new knowledge. The effect of local environment and aspects thereof on diet, physical activity and general health, nicely described by Ana Diez Roux $^{6}$, is an absolutely fascinating facet of public health nutrition, related to areas like city planning, sociology, human geography and architecture. Nutrigenetics ${ }^{7}$, metabolomics $^{8,9}$ and the emerging field of epigenetics ${ }^{10,11}$ open up completely new aspects of human nutrition, which will revolutionise the area of public health nutrition. 
Generous leadership can be interpreted in many ways; I would suggest that the ability to create consensus certainly belongs to the qualities required. To strive to let others get due credit and to have the ability to see a good compromise and to listen. A good leader recognises that ethical aspects of the science need to be highlighted, as well as transparency in our collaboration with stakeholders, as emphasised recently by Barrie Margetts ${ }^{12}$. There is a huge need for leadership in fostering equality and equity issues. More women need to be visible in nutrition leadership, in order to fully mirror the situation in our nutrition training programmes and in the workforce. We may need to identify ways to attract more young men into nutrition training programmes in some countries. Inequity, within and between countries, needs to be highlighted and acted upon. Also, good leaders need to push for more high-quality publications in the area of effectiveness of interventions, since the evidence base in most public health nutrition areas of intervention is still very weak.

Good communication skills are probably needed more today than ever. We need to be good and inspiring educators, using all possible venues and techniques for providing students with knowledge and skills. We need to inspire and provoke our students and teach our students how to find the relevant information rather than force-feed them. We need to identify careers for the emerging group of public health nutritionists.

The information pressure from nutritional science overall is tremendous with today's immediate electronic access. Medline provides titles from over 4800 scientific journals in biomedicine and related areas. In the mass media, we can see so-called scientific journalists being interviewed by other journalists on difficult issues regarding nutrition and health. Often charlatans get undeserved attention, when describing their new slimming diet or trying to sell products. The power of media celebrities in pushing the political agenda is tremendous and sometimes supportive: witness the effect in the UK of the chef Jamie Oliver on school meal provisions or the 'Oprah effect' on what books to read or what food to eat in the USA. Furthermore, when breakthrough scientific news ${ }^{13}$ is published, most of us get our telephone lines blocked by journalists trying to ask about recently launched findings we have not had access to yet. Just imagine thousands of public health nutritionists desperately trying to download, read and interpret just published findings. This is made even more difficult when the press release is issued even before the paper is made available online. There is absolutely no room for scientific arrogance any longer; if we do not respond to media questions several others are certainly willing to do so. The amount of 'others' responding to questions points directly to the issue that the new public health nutritionists need to have (1) a solid background on how to communicate with the media and (2) a good back-up source for information when it comes to rapid response to questions from journalists.

Within the communication skills, we certainly need to keep up with the increased need for lobbying for public health nutrition on all political levels. The European Commission, NIH and other funding bodies need to be lobbied to provide more funding for independent public health nutrition research. Governments need to be lobbied for sensible decisions regarding agriculture, trade, breastfeeding support and school lunch provisions, as well as to provide more funding for universities regarding research and training in public health nutrition. Future employers need to be lobbied for understanding the urgent need for posts for public health nutritionists.

The demands on a public health nutrition leader are thus HUGE, and can hardly be met by single scientists, but require networking and collaboration on a much broader scale than ever before. A number of things need to be sorted out within the near future in order for public health nutritionists to keep up with the rapid developments. Training programmes in public health nutrition need to be discussed, harmonised and politically supported. Regular updates on relevant topics need to be provided for practitioners. An 'early warning system' needs to be set up to provide a solid and relevant background for new scientific findings, as a service to the workforce. We need to discuss novel methods of dietary assessment and we need to set up guidelines for the design of good-quality interventions. We need to form a strong and vivid lobby for our cause. More than ever we need to meet and discuss in a melting pot of non-isolationism views of public health nutrition in relation to other aspects of nutrition and related disciplines.

This issue of the journal coincides with The First World Congress of Public Health Nutrition. The initiative for the First World Congress on Public Health Nutrition came from Professor Lluís Serra Majem. Congratulations to Lluís for the initiative and the success in attracting participants at this important event! Maybe we can take the opportunity of formalising our networking there?

We have a possibility of creating something new in Barcelona, an exciting open new arena for public health nutrition. Let us take the opportunity and the challenge!

\author{
Agneta Yngve \\ Editor \\ Department of Biosciences and Nutrition \\ Karolinska Institutet \\ Stockholm, Sweden \\ Email: agneta.yngve@prevnut.ki.se \\ DOI: $10.1079 /$ PHN2006977
}

\section{References}

1 Aristotle. Nicomachean Ethics. Cambridge: Cambridge University Press, 2000. 
2 The Giessen Declaration. Public Health Nutrition 2005; 8(6A): $783-6$.

3 Blackburn H. Diet and mass hyperlipidemia: a public health view. In: Levy RB, Dennis B, Ernst N, eds. Nutrition, Lipids and Coronary Heart Disease: A Global View. . New York: Raven Press, 1979.

4 Cannon G. Food and Health. The Experts Agree. London: Consumers' Association Ltd, 1992.

5 Ottawa Charter for Health Promotion, Bulletin of the Pan American Health Organization 1987; 21(2): 200-4.

6 Diez Roux AV. Residential environments and cardiovascular risk. Journal of Urban Health 2003; 80(4): 569-89.

7 Mutch DM, Wahli W, Williamson G. Nutrigenomics and nutrigenetics: the emerging faces of nutrition. FASEB Journal 2005; 19(12): 1602-16.

8 Gibney MJ, Walsh M, Brennan L, Roche HM, German B, van Ommen B. Metabolomics in human nutrition: opportunities and challenges. American Journal of Clinical Nutrition 2005; 82(3): 497-503.

9 Roche HM, Phillips C, Gibney MJ. The metabolic syndrome: the crossroads of diet and genetics. Proceedings of the Nutrition Society 2005; 64(3): 371-7.

10 Oommen AM, Griffin JB, Sarath G, Zempleni J. Roles for nutrients in epigenetic events. Journal of Nutritional Biochemistry 2005; 16(2): 74-7.

11 Waterland RA, Jirtle RL. Early nutrition, epigenetic changes at transposons and imprinted genes, and enhanced susceptibility to adult chronic diseases. Nutrition 2004; 20(1): 63-8.

12 Margetts B. Stopping the rot in nutrition science [editorial]. Public Health Nutrition 2006; 9(2): 169-73.

13 Yngve A, Hambraeus L, Lissner L, Majem LS, Vaz de Almeida MD, Berg C, et al. The Women's Health Initiative. What is on trial: nutrition and chronic disease? Or misinterpreted science, media havoc and the sound of silence from peers? Public Health Nutrition 2006; 9(2): 269-72.

\section{Achieving the Millennium Development Goals through mainstreaming nutrition: speaking with one voice}

At the most recent meeting of the Standing Committee on Nutrition of the UN system in Geneva in March of this year (2006), there was a dramatic shift in the tenor of the opening plenary session. Three very high-ranking officials of three of the largest implementing UN agencies (WHO, UNICEF, World Bank), along with WFP and FAO, produced - independently of one another - a clear, consistent message focusing on the importance of nutrition for development. In each case this was couched within the comparative advantage of each agency.

It was also striking that none of the speakers came from a background of nutrition training - one economist, one public health physician, one health economist and one development expert. All had been converted by enthusiastic nutrition colleagues within their particular agency, and by long experience in many countries, and an expanding evidence base. All referred to the same evidence base - the Bellagio Child Survival Study Group ${ }^{1}$ and subsequent papers, published not in nutrition or even public health journals but in medical journals (the Lancet and the British Medical Journal in particular), although the significance of this will not be discussed here. But all were somewhat perplexed as to why nutrition issues were not an automatic component of all national health and development programmes, including within each agency. They had clearly used their considerable experience in the public sector to think this through, especially the importance of having a common and consistent message.

Another remarkably common theme from all these speakers was the extent to which attainment of the
Millennium Development Goals (MDGs) is at the top of their agendas and is now driving all programme planning and implementation. The insight - known to all working in nutrition and development - that reaching the MDGs will require mainstreaming of nutrition interventions in at least six of the goals and perhaps all eight ${ }^{2}$ seems to have reached a number of influential ears. Equally, all accepted without question that national development does not happen without improved nutrition and health and a reduction in inequities; i.e. nutrition is not only an outcome of economic development, but an essential input to all such development. All of this raises a rephrasing of the old question: when will nutrition stop being the Cinderella of health interventions when it comes to global funding priorities? Why, for example, is there no Global Fund for broad-based nutrition programming?

A further striking commonality was that they came with the same request to all those present, as well as to the wider public health nutrition sector in general: agree on terminology, agree on the same priorities and simplify the message. They all promised that if these three things were to happen, they would push nutrition programmes and advocate for nutrition funding and programming within their agencies.

Some may rightly say that nutrition is intrinsically more complex than some other public health interventions such as immunisation. The UNICEF conceptual framework is widely accepted as the basis for the analytical framework of nutrition problems and may be one basis for common approaches, but with the increasing understanding that all three groups of factors must be addressed: immediate 